\title{
Malzeme ve İnşa Süreçlerinin Yeniden Tasarlanması: Bruder Klaus Şapeli ve Betonarmenin Potansiyeli
}

\author{
Öğr. Gör. Nazmiye Öztürk
}

\section{Özet}

Günümüz mimarlık gündemini belirleyen güncel tasarımların çoğunda alt parçalardan bütüne doğru, malzeme ve inşa süreçlerinin tasarımın bir parçası haline gelmesi dikkat çekicidir. Mimarlık tarihinin en eski örneklerine bakıldığında da benzer bir durum görülmektedir: Mısır Piramitlerinde, taşların şekillendirilmesi ve bir araya getirilmesiyle geometrik bütünlük elde edilmiş, simgesel anlam ve anıtsalığa ulaşılmıştır. Bu yazıda malzemenin tasarlanmasına bağlı iki olgunun izi sürülmektedir: 'malzeme ve inşa süreçleri yoluyla anlam bütünlüğü' ve 'malzeme potansiyellerinin açığa çıkarılması'. Bu iki düşüncenin paralelinde Peter Zumthor'un tasarladığı Bruder Klaus Şapeli ve betonarmenin standart olmayan bir yolla kullanımı örnek olarak ele alınmıştır.

\section{REDESIGNING MATERIALS AND THEIR CONSTRUCTION PROCESS: BRUDER KLAUS CHAPEL AND POTENTIAL OF CONCRETE}

\footnotetext{
Abstract

In the contemporary buildings determining today's architecture, materials and their construction processes have become a part of design. Looking at the history of architecture the ancient examples have similar situation: In the Egyptian pyramids, symbolic and monumental meaning has been achieved through shaped stone pieces and how they brought together to get the whole geometry. This paper traces two phenomena related to material design: "Content integrity via material and its construction process" and "Emerging of material potentials". In this paper Peter Zumthor's Bruder Klaus Chapel was examined as an example of these two points above.
}

Anahtar Kelimeler

Mimarlık

Malzemelerin Yaratıcı Kullanımı

\section{Keywords}

Architecture

Creative Usage of Materials 


\section{Giriş}

Anıtsallık ve malzeme arasında ilk bakışta belirgin olmasa da doğrudan bir ilişki vardır ve Norberg-Schulz, Mısır Mimarisini ele alırken buna değinir: "Mısır piramitlerinde sert ve dayanıklı olduğu için taş seçilmiş ve keskin kenarlarla yumuşak yüzeylerin zıtlığı yoluyla taşın doğal karakteri artırılmıştır. Kütle ve doluluk böylece sembolik organizasyonun bir parçası olması için soyutlanmıştır... Buna mutlak mekan ve tekil bir yapının onu oluşturan malzeme gibi davranması diyebiliriz" ( Norberg-Schulz,1983:6). Norberg-Schulz'un bu sözleri iki noktada dikkat çekicidir. Birincisi piramitlere malzeme açısından yaklaşması diğeri ise malzemenin doğal karakterinin artırılabileceğine ilişkin ifadesidir.

Piramitler kendi adında form ve geometriyi içermesine rağmen, onları oluşturan malzemenin nasıl öncelikli bir açıklama aracı haline gelebildiği önem taşımaktadır. Asal geometrilerden biri olan bu form, Piramitlerin zamana dirençlerini tek başına açılayabilir değildir. Burada form, geometri ve ölçeğin yanı sıra elzem bir değişken olarak malzeme ve onun kullanımı söz konusudur. Piramitlerde kullanılan doğal taş, doğadaki amorf halinden çıkarılarak düzleştirilmiş ve bu parçalar yıllar süren zorlu çalışmalarla basamaklanarak organize edilmiştir. Piramitlerdeki basamaklanma, taşın yığma mantığının bir zorunluluğu olarak anıtsal etki alanını oluşturucu ögelerden biridir. Anıtsal yapıların zamana dayanımı, ölçek ve geometriye bağlı simgesel ve sembolik anlamlardan çok, malzeme odaklı ve dolayısıla inşai süreçlerdeki hassasiyetle ilişkilidir. Diğer bir deyişle malzeme ve inşa süreçleri tasarımsal bir bütünlüğe doğru örgütlendiğinde yapının simgesel ve sembolik anlamı güçlenmektedir.

Norberg-Schulz'da ikinci nokta, malzemenin doğal karakterinin artırıldığına ilişkin ifadedeki tasarım imasıdır. Bu noktayı paradoksal ve dolayısıyla dikkat çekici yapan özellik, özellikle o çağlarda malzemelerin zaten yeterince doğal olduğu gerçeğidir. Bu anlatım bir bakıma 'bir malzemenin sahip olduğu potansiyeller nasıl açığa çıkarılabilir?' sorusuna karşılık gelmektedir. Piramitler üzerinden bu soru şöyle cevaplanabilir: doğal taşın amorf formu düzleştirilerek taşın modül blok oluşturabilme potansiyeli açığa çıkarılmıştır. Bu soru, yalnızca doğal olanlara değil tüm malzemelere yönlendirilebilecek bir sorudur ve tasarım bu soruyu yanıtlayabilecek bir araçtır. 
'Malzeme ve inşa süreçleri yoluyla anlam bütünlüğü' ve 'malzeme potansiyellerinin açığa çıkarılması' denilebilecek bu iki nokta, esasında, tasarlama eylemini içsel ve zihinsel bir süreç olduğu yönündeki yaygın görüşü sorgulamaktadır. Politzer'in Felsefenin Temel illkeleri'nde yer verdiği Engels'ten bir alıntı, dış dünya ve düşünceye ilişkin alternatif görüşü şöyle dile getirmektedir: "Fikir, maddi dünyanın insan zihnine yansımasından ve düşünce biçimlerine dönüşmesinden başka bir şey değildir" (Politzer, 2009:59). Peter Zumthor da fikirlerin maddede gizli olduğu yönündeki yazılar (Zumthor, 1998) ve yapı örneklerini mimarlık ortamına sunan bir mimar olarak bilinmektedir. Zumthor, "Güzelliğin Sert Çekirdeği" isimli yazııındaki "Mimarlık gerçekliği, mekan, hacim ve formlardan meydana gelen maddesel kütledir (Zumthor, 2001). Fikirler sadece nesnelerin içindedir ve onların dışında hiç bir fikir bulunmaz" (Zumthor, 1998:34) sözünden de anlaşılacağı gibi, madde ve malzemenin içinde var olan potansiyellere dikkat kesildiği söylenebilir. Zumthor'un bu düşüncelerle tasarladığı birçok yapı arasında Bruder Kalus Chapel'i malzemedeki potansiyelin nasıl açığa çıkarılacağı sorusuna verilmiş bir yanıt gibidir.

\section{Bruder Klaus Şapeli ve Şapelin Etki Alanı}

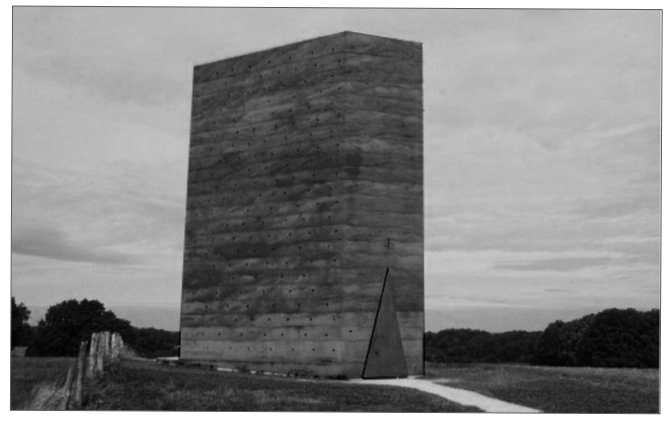

Görsel 1. Brother Klaus Şapeli²

1. Benjamin, 2003. Walter Benjamin, teknolojinin genelde gerçekliğe, özelde sanata bakışı değiştirmesi olgusu üstüne yoğunlaşmış, mekanik yeniden üretimin bütün bir çağa damgasını vurmasına bağlı olarak sanatın bütün sahiciliğini kaybettiğine yönelik genel savını, aura (etki alanı) çözümlemesi üzerinden açıklamıştır. Benjamin, özgün bir sanat yapıtının her yeniden üretimiyle birlikte "aura"sından bir şeyler daha yitirdiğini ileri sürmektedir (http://www.felsefeekibi.com/dergi6/s6_y2.html). Bruder Klaus Şapeli malzemenin seri üretim ve standartlarının dışına çıkmış, kendi yapım yasalarını yeniden oluşturmuş ve etki alanını (aurasını) bu yolla edinmiş bir yapı örneği sayılabilir. Malzeme potansiyellerinin tasarım yoluyla açığa çıkarılması ile sınırlandırılmış bu yazı, seri üretilmiş nesne ve sanat eseri arasındaki farkın tartışıldığı, Walter Benjamin'in (1892-1940) sanat eserinin aurası kavramına kadar kapsamlı bir tartışma yol açabilecek bir bağlamdadır.

2. http://www.beton-campus.de/2011/07/stampfbeton-bauen-mit-haenden-und-fuessen/ 
Almanya'nın Köln kentinin 50 kilometre güney batısında bulunan Machernich'teki Wachendorf köyünün tepelerinde yer alan Bruder Klaus Şapelinin, 2007 yııının Ekim ayında açılışı yapılmışır.

Bruder Klaus Şapelini ilk ziyaret eden dergi ve gazete yazarlarının izlenimleri ortak bir noktada toplanmaktadır: Jonathan Glancey, The Guardian'da yazmış olduğu Solitary Refinement (Issız Sadelik) isimli yazısında mitler, efsaneler ve büyülere ait bir yapı gördüğünü şu cümlelerle ifade etmektedir: "Tepelerde, çöl kumları üzerinde veya uzak adalarda yükselen ve bizleri başka bir dünyaya taşıma gücüne sahip gizemli, yalnız strüktürler...Bunlar mitlerin, efsanelerin ve büyülerin unutulmayan mimarisi" (Glancey, 2007). Andreas Rossman Detail dergisinin Şubat sayısında, şapelin insanı huşu içinde bırakan bireyselliğiyle gökyüzüne yükseldiğini yazmaktadır. Icon dergisinde ise Beatrice Galilee yazısına şöyle başlamaktadır: "Sisli bir Çarşamba sabahı saat 6'da Almanya'nın güneyindeki sessiz bir arazide Peter Zumthor'un Bruder Klaus Şapeli ile yalnız kalınmalı..." (Galilee, 2007). Mimarlık ve tasarımla ilişkili yazarlardan aktarılan bu alıntılarda dikkati çeken ilk olgu, yoğun ve kelimelere dökülmesi zor bir etkilenmeyi ifade etme çabasıdır. Genel olarak değerlendirildiğinde yazılarda, ilk izlenimler ve yapıyla ilgili genel bilgiler yer almakta; ayrıntılara geçmeden önce, yapının manevi derinliği üzerine sözlerin şiirsel bir dille kaleme alındığı görülmektedir. Bu şiirsel anlatımlardan yapının ilkin anıtsal sonrasında mistik bir etki yarattığı söylenebilir.

Yapı dışarıdan ilk bakışta dolu bir kütle görüntüsüne sahiptir. Bu mono-blok kütle, içinde mekân barındıran bir yapı imasından çok bir nesne görünümü sunmaktadır. Nesne görünümlü yapılar, çoğunlukla işlevin dışarıya yansıdığı silo veya su deposu gibi işlev makinalarına benzetilebilecek türde üretim odaklı yapılardır. Bu tür yapıların herhangi bir gösteriş iddiası yoktur. Şapelin kütleselliği de benzer şekilde dışarıya yönlenmiş bir biçim kaygısına sahip değildir.

Güncel mimarlıkta cephenin tasarımı ayrı bir uzmanlık alanı olarak görünmeye başlamışır. Yapı cepheleri bu yönde ne kadar dikkat çekici ve albenili tasarlanırlarsa o derece başarılı sayılmaktadır. Zumthor'un şapel cephesindeki tutumu sadelik olarak görülebilir. Ancak burada mimarın birincil amacının sadelik oluşturmak olmadığı, yapının süreçler sonucu sadeliğe ulaşıı̆ı, araştırmalardan derlenen aşağıdaki bilgilerden çıkarsanmaktadır. 


\section{İşverenler ve Mimar}

Bruder Klaus Şapeli bölgede yaşayan ve tarımla uğraşan çift Hermann Josef Scheidtweiler ve Trudel Scheidtweiler tarafından yaptırılmıştır. Kendi arazilerinde iyi ve mutlu bir hayata teşekkür için "Brother Klaus" olarak bilinen kutsal Nicholas von Flüe'ye adadıkları şapelin inşasında bizzat kendileri mimarla birlikte çalışmışlardır.

Köln'deki Kolumba Sanat Müzesi ek binası yarışmasını kazanan Peter Zumthor'un tasarımından çok etkilenen çift, mimara bir mektupla şapel yaptırmak istediklerini yazmış ve süreci başlatmışlardır (Galilee, 2007). İsviçreli Mimar Peter Zumthor dünya mimarlık ortamının en prestijli ödülü sayılan Pritzker Ödülüne 2009'da layık görülmüştür. Yapı tasarlarken kendisini harekete geçiren düşünceleri anlattığı Thinking Architecture başta olmak üzere, Atmospheres, Therme Vals, Kunsthaus Bregenz, Spirit of Nature Wood Architecture gibi kitapları bulunmaktadır.

\section{Yapı Geometrisi}

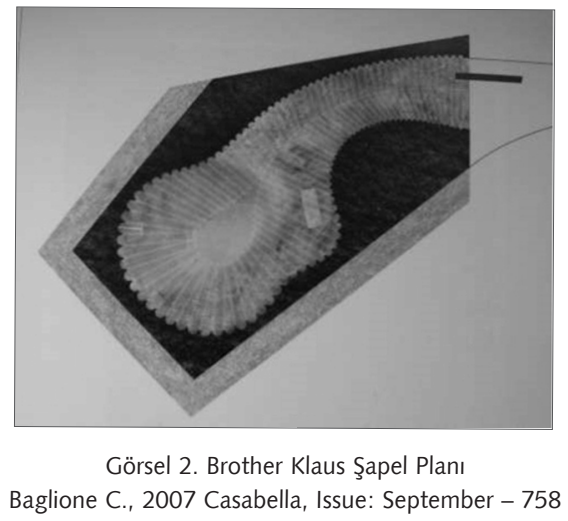

Şapel yapısının ayrıntılarına yer vermek gerekirse, 12 metre yüksekliğinde olan yapının plan geometrisi Görsel 2'de görüldüğü gibi dışta düzgün olmayan bir beşgen formundadır. Beyaz çimento ve o bölgede bulunan sarı renkli kumlar kullanılarak betonarme sistemin farklı bir yolla uygulamasıyla yapılmış olan duvarlar (Baglione, 2007:14) dışarıdan düz, ancak yapının içinde düz olmayan içbükey ve dışbükey yüzeyler olarak devam eder. Yapının içi dışarıdan algılanmayan farklı bir 
geometriye sahiptir ve bu geometriyi örneğin metrekare olarak ölçmek zordur, hacmini hesaplamak ise daha da karmaşık matematiksel işlemler gerektirir. Dikdörtgenler prizması türevi mekânlar içinde yaşandığı dikkate alındığında bu yapı, bildik olmayan ve karmaşık geometriye sahip bir iç mekâna sahiptir.

\section{İnşa Süreci}

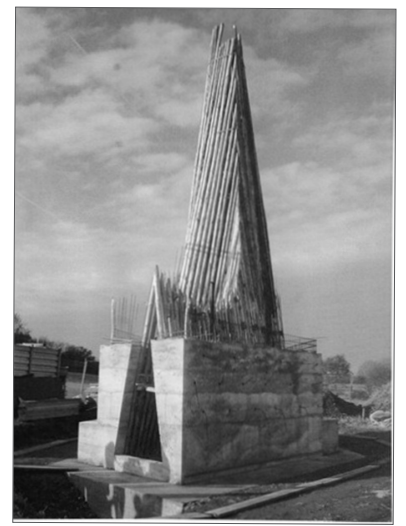

Görsel 3. Kalıp ve Beton İlişkisi ve Yapının İnşa Süreci Baglione C., 2007

Bu yapının içinde Zumthor, kalıp olarak civardaki ormanlardan edinilmiş 120 adet ağaç kütüğü kullanmıştır. Ağaç kütükleri, Görsel 2'deki planda ve Görsel 3'de görüldüğg̈ gibi yukarıda birbirlerine birleşerek içerinin kalıbını oluşturur. Her ay 50 santimetre beton dökülerek yirmi dört katmandan oluşan duvarlar iki yılda tamamlanmıştır. Her katman günün bir saatine karşlık gelmekte ve insanın günlük işler tarafından kuşatılmışlığı fikrini temsil etmektedir. Duvarlar tamamlandıktan sonra içerideki kalıp, ateşe verilerek yapının kaba inşaat tamamlanmıştır (Rossman, 2008:14).

\section{Program ve Mistik Öğeler}

Bu şapel yapısı programatik olarak dış uyarııılardan soyutlanması gereken bir ibadet mekânıdır. Gün içinde gece görüntüsü denilebilecek bu soyutlamanın tasarımdaki bileşen karşııkları, tütsülenmiş koyu renk duvarlar, duvarlara gizlenmiş cam kürelerin yıldız etkisi, çatıda açık bırakılan gökyüzü penceresinin parlak ışığı (Görsel 5) ve yansıtıcı 
zemindir. "Dışarıdan kum rengi görümündeki bu katmanlı duvarlar içeride yanan ahşabın etkisiyle siyahlaşmış ve mistik bir iç mekân elde edilmiştir" (Galilee, 2007). Ancak Scheidtweiler çifti, Peter Zumthor'un yanma işlemi sonrasındaki duvar rengini yeterince siyah bulmadığını, doğru rengi elde etmek için yedi gün boyunca tütsüleme işlemine devam ettiklerini ifade etmektedir. "Duvarlara sinmiş kendine özgü bir koku"nun bu mistik etkiyi artırdığı yapıyı ziyaret edenler tarafından söylenmektedir Yapının üç metre yüksekliğindeki büyük üçgen kapısından girildikten sonra bu mistik etkiyi en uç noktalara taşımak amacıyla birçok unsurun daha tasarlanmış olduğu görülmektedir (Galilee, 2007). Bunların en güçlüsü yapının tepesindeki boşluktur. İç mekânın karanlık duvarlarından yukarı bakıldığında görülen ışık boşluğu gece gökyüzünde parlak bir yıldız imgesine gönderme yapılmaktadır. Diğer mistik unsurlardan biri duvarlarda yapım esnasında yerleştirilmiş beş santimetre çapında 350 adet metal boru delikleridir. Scheidtweiler'ların komşularından edindikleri bira yapımında kullanılan bu pipetler, içerideki kütüklerin yanması esnasında dumanın çıkışını sağlamış ve daha sonrasında gökyüzündeki yıldız parıltıları etkisini sağlamaları için temizlenerek içlerine cam küreler yerleştirilmiştir.

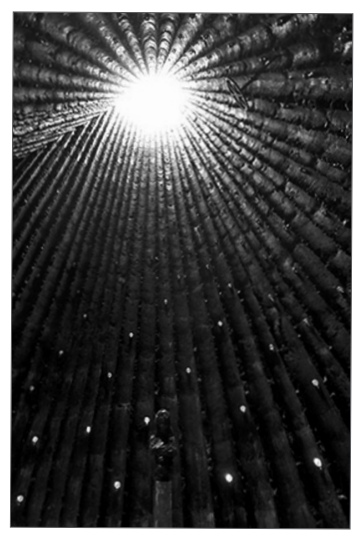

Görsel 4. Şapel iç Mekanında Gökyüzü Penceresi Baglione C.2007 

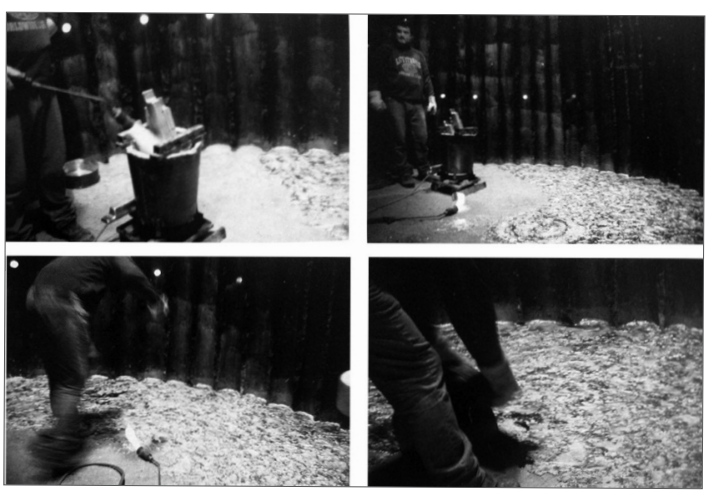

Görsel 5. Eritilmiş Kurşun Kaplama Zemin Yapımı, Baglione C.,2007

\section{Zemin}

Bugünün bilinen yapım teknolojilerinden farklılaşma zeminde de sürdürülmektedir. Eritilmiş kurşun kaplama sayesinde zemin donmuş bir havuza benzetilmiştir. Tasarımda yukarıdaki gökyüzü penceresinden gelecek olan yağmur suları zeminin ortasında küçük bir havuz oluşturmaktadır. Ancak uygulama sırasında yeterince kalın dökülemeyen kurşun tabakanın altındaki kızıl kahverengi kil tabakası zeminde biriken suyu absorbe etmekte ve su birikmesini engellemektedir (Baglione, 2007 s:151).

\section{Bruder Klaus Şapelinde Tasarım ve Betonarme}

Beton, plastik bir malzeme olarak içinde demir çubuklardan yapılmış donatıları ve sertleşene kadar ona şekil veren kalıbı ile birlikte betonarme haline gelir. Betonarme yapı malzemesi olarak kullanılmadan önce, onun yapıda kullanılma potansiyelleri üzerine çalışılmış ve oldukça yaratıcı çözümler ortaya çıkmıştır. Betonarme saksı ve tekneler bu çözümlere örnek olarak gösterilebilir. Kalıp betonarmede öylesine önemlidir ki kalıp olmaksızın betonarme bir yapı inşa edilemeyeceği gibi, kalıba bağlı olarak betonarmeyi bir hamur gibi yoğurabilir, yapı bileşenleri (duvar, perde, kolon, kiriş, merdiven, döşeme vb.) ayrık değil, kaynaşmış bileşenler haline getirilebilir. Fakat tarihsel sürece bağlı zorunluluklar, betonarmenin potansiyellerini araştırmak ve artırmak yerine onu standart bir yapım sistemi haline getirmiştir. İkinci dünya savaşından sonra artan konut ihtiyacını karşılamak için inşaat süresinin hızlandırılması amacıyla geliştirilen prefabrikasyon ve tünel kalıp 
sistemleri, bugünün betonarme yapım teknolojisi standardını oluşturmuştur. Bu standartlaşma, gündelik hayatı doğrudan etkilemektedir.

Yapının inşa süreci, teknolojik boyut olarak kabul edilirse, bu teknolojik boyutun düzeyini çeşitli gelişkin düzeyler ile karşış̧tırarak açığa çıkarmak mümkündür. Örneğin betonarme yapım teknolojisinin, tünel kalıp sistem ile birlikte kullanımı bilinen en hızlı yapım teknolojilerinden biridir. Hız üzerinden değerlendirildiğinde, Zumthor'un kullandığı yapım teknolojisi, tünel kalıp sisteme göre oldukça geri bir teknolojidir. Şapel, işveren ve komşularından oluşan dört kişilik bir ekip tarafından yapılmıştır ve tamamlanması iki yıl üç ay sürmüştür. Fabrikada seri olarak üretilen, mevsimlerin yapım süreçlerini etkilemediği hızlı prefabrikasyon yapım teknolojileri ile karşılaşııııldığında, bu yapı ağır ilerleyen bir süreçte ve yerinde imal edilmiştir. İnşa Süreci başlığı altında yapılan araştırmaya göre duvar, her ay bir katmanı dökülen ve beklemeye bırakılan yirmi dört katmandan oluşmaktadır. Burada betonarmenin, iskelet değil yığma sistem mantığında kullanılması, yapının tasarımındaki alışımadık bir diğer özelliktir.

Bu ölçekte bir yapı için ayrılan yapım süresinin oldukça uzun olması dezavantaj gibi görünse de, bu durum zamanın, yapı bileşenleri üzerinde nitelik olarak kendini göstermesine olanak tanımaktadır. Beton duvarlardaki katman izlerini belirginleştiren bekleme süresi, bu sürecin kendisinin de tasarımın bir parçası haline getirildiğine işaret etmektedir.

Şapel, dünyanın herhangi bir noktasında yeniden inşa edilecek olsa aynı yapıyı elde etmek hemen hemen olanak dışıdır. Bunun nedeni yapımında kullanılan malzemelerin o bölgeye özgü olmasıdır. Betonarmede kullanılan kum, kalıpta kullanılan ahşap buna örnek olarak gösterilebilir.

\section{Sonuç}

Malzemelerin potansiyelleri üzerine yeniden düşünmek ve tasarım yoluyla bunu açığa çıkarmak güncel mimarlık için önemlidir. Bu tür arayışlar malzemelerin yeniden tasarlandığı yaratıcı inşa süreçlerini beraberinde getirecektir. Bu yazıda Peter Zumthor'un tasarladığı Bruder Klaus Şapeli tüm bu noktalara örnek olarak ele alınmıştır. 
Bu yapıda, mimar tarafından betonarme yeniden keşfedilmiş gibidir. Yakılmak üzere ağaç kütüklerinden kalıp oluşturmak, süreci bir standardın izinden sürdürmek yerine, başlangıç noktasından yeniden başlatmaktır. Keşfedilmiş olan bilinen ögelerin kişisel olarak yeniden keşfedilebileceğinin örneğini sunan bu tasarım Louis Kahn'ın 'bilinmeyene geri dönme' kavramını çağrıştırmaktadır. Beton gibi sıradan denilebilecek bir yapı malzemesini kullanarak etki gücü yüksek ve anıtsal bir yapının tasarlanabilirliği Norberg Shulz'un 'malzemenin doğal karakterinin artırıması'nın güncel örneği kabul edilebilir.

Bu örnek göstermektedir ki; malzemede ve uygulamada keşfedilmeyi bekleyen potansiyeller vardır. Bunların açığa çıkarılması tasarım aklını yükseltmek için gerekli bir araç olarak görülmelidir. Mimarlar yapı teknolojilerini ve malzemelerini standartlaşmış bir yolla tekrarladıkları sürece güncel olmayan yapıların her geçen gün artmaya devam etmesi kaçınılmaz görünmektedir. Katalogdan seçim yapmak yerine malzemelerin tasarımı tetikleyici özlerini açığa çıkarmanın, tasarımcı mimarların yükümlülüklerinden biri olduğu unutmamalıdır. 


\section{Kaynakça}

Baglione, Chiara, "Nel Silenzio" Casabella, Sayı: 758 September $-2007: 151$.

Benjamin, Walter, "Mekanik Yeniden Üretim Çağında Sanat Eseri", Edebiyat Eleştiri Dergisi, Mart-Haziran, Sayı:2/3, 2003.

Galilee Beatrice, "Bruder Klaus Chapel", Icon, Sayı:050-August 2007.

Glancey, Jonathan, "Solitary Refinement", The Guardian, 19 July 2007.

Norberg-Schulz, Christian, Meaning in Western Architecture, NewYork: Rizzoli International Publications, 1983.

Politzer, Georges, Felefenin Başlangıç İlkeleri, Çev: Sevim Belli, İstanbul: Sol Yayınları, 2009.

Rossman, Andreas, "Feidkapelle in Wachndorf", Detail Sayı:1/2. 2008.

Zumthor, Peter, Thinking Achitecture, Basel: Brikhauser Publishers For Architecture, 1998.

Zumthor, Peter, "Güzelliğin Sert Çekirdeği" Arredamento Mimarlık, Sayı:2001-4, İstanbul: Boyut Yayın Grubu, 2001.

http://www.beton-campus.de/2011/07/stampfbeton-bauen-mithaenden-und-fuessen/ [Erişim Tarihi: 27 Ağustos 2012]

http://www.iconeye.com/read-previous-issues/icon-050-\% 7Caugust-2007/bruder-klaus-chapel-\% 7C-icon-050-\% 7C-august-2007 [Erişim Tarihi: 03 Temmuz 2013]

http://www.guardian.co.uk/artanddesign/2007/jun/11/architectu re [Erişim Tarihi:13 Nisan 2013]

http://www.felsefeekibi.com/dergi6/s6_y2.html [Erişim Tarihi:03 Temmuz 2013] 